\title{
Possibilidades conceituais da sociologia das ausências em contextos de desqualificação social
}

\author{
Alex Pizzio $^{1}$ e Marília Veríssimo Veronese ${ }^{2}$ \\ Programa de Pós-Graduação em Ciências Sociais da Unisinos
}

\begin{abstract}
Neste trabalho, abordamos questões relativas às situações de pobreza vivenciadas por uma parcela significativa dos trabalhadores brasileiros na contemporaneidade. Na parte inicial do artigo revisamos autores que tratam da questão da pobreza, seja através das idéias de marginalização, inclusão marginal ou desqualificação social. Entende-se que a reconstrução histórica do processo de desqualificação social pode ajudar a compreender como as estruturas sociais impõem-se aos atores com poder constitutivo, forjando modos de subjetivação e atuando sobre a base psicossocial dos indivíduos. Na segunda parte, propomos a utilização de conceitos teóricos de Boaventura de Sousa Santos na pesquisa social com sujeitos em situação de desqualificação social, como referencial capaz de dar conta (pelo menos parcialmente) da compreensão dessa complexa realidade.
\end{abstract}

Palavras-chave: Pobreza, Desqualificação social, Sociologia das ausências.

Conceptuals possibilities of sociology of absences in contexts of social unqualification

In this work, we develop issues on situations of poverty experienced by a significant share of Brazilian workers in contemporaneity. In the first part of the article, we review authors who deal with poverty issues, be it through the ideas of marginalization, marginal inclusion or social unqualification. It is assumed that the historic reconstruction of the social unqualification process can help understand how social structures stand out before actors with constitutive power, making up subjectivation modes and acting on the psychosocial base of individuals. In the second part, we propose the usage of theoretic concepts by Boaventura de Sousa Santos in his social research with subjects under situation of social unqualification, as a referential source capable of explaining, at least partly, this complex reality.

Keywords: Poverty, Social unqualification, Sociology of absences.

\section{A pobreza e a desqualificação social}

A s transformações sofridas pelo mercado de trabalho, eventualmente, têm se constituído Lem situações catastróficas para o trabalhador, uma vez que implicam na sua exclusão ou na inclusão precária nesse universo. Assim, a precarização das relações de trabalho, intensificada com a adoção de procedimentos que priorizam a substituição do trabalho vivo por trabalho morto, tem fragilizado sobremaneira a situação dos trabalhadores em geral, inclusive os mais qualificados, mas com maior gravidade entre os menos qualificados (Antunes, 1999). Em decorrência, observa-se um grave processo de degradação do trabalho e do trabalhador, com efeitos dessocializantes no âmbito das famílias trabalhadoras e no aperfeiçoamento da cidadania (Ivo, 2001).

Essa realidade tem sido objeto de interesse de vários setores da sociedade, entre eles o meio acadêmico. Como destaca Véras (2003), cada vez mais estudos têm se dedicado à compreensão dessa degradação, do enfraquecimento dos vínculos sociais e dos riscos de marginalização de segmentos amplos da população. Seguindo essa tendência, o sociólogo

1 Doutorando no Programa de Pós-Graduação em Ciências Sociais da Unisinos.

2 Doutora em Psicologia pela PUCRS. Docente e pesquisadora do Programa de Pós-Graduação em Ciências Sociais da Unisinos. 
francês Serge Paugam, ao analisar as transformações do mercado de trabalho e suas conseqüências para os indivíduos, concluiu que essas mudanças seriam responsáveis por um processo que ele designou de desqualificação social (Paugam, 1999). Sua abordagem traz à discussão os estigmas relacionados às condições de vida degradadas ou precarizadas e ganha complexidade teórica na medida em que não é apenas uma forma de referir-se a velhos problemas, mas aponta para a temática da chamada nova pobreza.

Para Paugam, falar em desqualificação social significa abordar questões relativas à situação de pobreza vinculadas aos processos de exclusão do mercado de trabalho. Trata-se de um processo abrangente, dinâmico e de múltiplas dimensões; pelo fato de valorizar o caráter multidimensional e evolutivo da pobreza, o estudo da desqualificação social significa:

(...) estudar a diversidade dos status que definem as identidades pessoais, ou seja, os sentimentos subjetivos acerca da própria situação que esses indivíduos experimentam no decorrer de diversas experiências sociais, e, enfim, as relações sociais que mantêm entre si e com o outro (Paugam, 2003, p. 47).

De acordo com o autor, nas sociedades modernas a pobreza não é somente o estado de despossuir; ela corresponde a um status social específico, "inferior" e desvalorizado, que marca profundamente a identidade de todos os que vivem essa experiência (Paugam, 2003, p. 46).

A pobreza, caracterizada como desqualificante, alude a condições precárias de vida vistas como ameaça à coesão social. Em outras palavras, fala-se aqui de uma precariedade econômica e social que revela a existência de um contingente de indivíduos economicamente desnecessários e supérfluos, ao mesmo tempo em que supostamente exporiam um modo de vida caracterizado pela instabilidade conjugal, pelo baixo nível de participação nas atividades sociais e por uma vida familiar "inadequada".

Se, por um lado, a construção conceitual da desqualificação social abrange situações de pobreza, por outro, ela está vinculada a processos de exclusão. Paugam articula três idéias ao conceito de desqualificação social, que se encontram igualmente vinculadas ao conceito de exclusão. A noção de trajetória, ou seja, de que há um processo que deve ser percebido de forma longitudinal, o que permite apreender o percurso temporal dos indivíduos; o conceito de identidade, positiva ou negativa, de crise e de construção dessa identidade e, por fim, o aspecto da territorialidade, ou seja, a base espacial que abriga processos excludentes. Do mesmo modo, buscando destacar o caráter processual implícito na noção de desqualificação, o autor enfatiza as fases que a compõem: a fragilidade, a dependência e a ruptura.

A fragilidade está relacionada à experiência vivida da deslocalização social. Essa deslocalização diz respeito a experiências como a dificuldade de inserção profissional e a perda de referências, como o local de moradia, por exemplo. Trata-se de experiências tipicamente dolorosas, que produzem, em quem as vivencia, a sensação de estar deslocado. Nesse sentido, Paugam enfatiza que "uma situação continuada de fragilidade pode conduzir à fase da dependência” (2003, p. 34).

Segundo as conclusões do autor, a dependência é de fato a fase em que os serviços sociais responsabilizam-se pelas dificuldades enfrentadas pelos indivíduos. A maioria das pessoas que vivenciam essa situação, em boa medida, desistiu de ter um emprego. Os que "vivem a experiência da dependência procuram compensações para suas frustrações tentando valorizar sua identidade parental, sua capacidade para cuidar do lar e exercer diversas atividades em suas comunidades" (Paugam, 2003, p. 38). Por fim, a continuidade da dependência pode levar à experiência da ruptura.

A ruptura constitui-se em uma experiência na qual os indivíduos vivenciam um acúmulo de dificuldades, tais como afastamento do mercado de trabalho, problemas de saúde, 
falta de moradia, perda de contatos com a família etc. Trata-se da última fase do processo, produto de uma soma de fracassos que conduzem a uma acentuada marginalização.

O autor vincula a desqualificação social à construção de uma identidade, de um status e à condição social objetiva das populações reconhecidas como em situação de precariedade econômica e social. Para ele, o tema da desqualificação social não pode ser estudado de forma aprofundada sem referência a uma hierarquia dos status sociais.

Se o seu trabalho teve como referência a experiência européia, especialmente a francesa, pode-se transferir essa análise para a realidade da classe que vive do trabalho no Brasil, já que as transformações, embora tenham tido efeitos diferenciados na periferia do sistema-mundo globalizado, foram de certa forma mundiais. Sua teorização foi inspirada no pensamento de Erving Goffmam, sobretudo em seus trabalhos relacionados ao estigma. Segundo Paugam, Goffmam (1988) examinou "a relação entre a identidade social e a identidade pessoal".

A identidade pessoal e a identidade social de uma pessoa, antes de mais nada, dependem do cuidado que os outros têm de a definir. Quanto à identidade pessoal, é freqüente que um tal cuidado se manifeste já antes do nascimento e perdure após a sua morte; então, para essa pessoa, não se trata de sentimentos, de identidade ou outros. Em contrapartida, a identidade em si é, antes de tudo, uma realidade subjetiva, reflexiva, necessariamente experimentada pelo indivíduo em questão (...) Certamente, o indivíduo se vale, para construir uma imagem de si mesmo, de materiais iguais aos utilizados pelos outros para construir-lhe uma identificação social e pessoal. E ele não exerce nisso grau menor de liberdade quanto ao estilo de construção (Goffmam, citado por Paugam, 2003, p. 61).

Desse modo o conceito de identidade social desenvolvido por Goffman, "permite dar prosseguimento à análise da designação ou da rotulagem, bem como examinar o controle da informação que um indivíduo pode exercer sobre a deficiência ou descrédito que o caracterizam" (Paugam, 2003, p. 61).

A partir desses elementos e tendo a assistência social como eixo transversal do processo, o autor explicita ainda mais seu conceito do processo de desqualificação social:

O movimento de expulsão gradativa, para fora do mercado de trabalho, de camadas cada vez mais numerosas da população - e as experiências vividas na relação de assistência, ocorridas durante as diferentes fases desse processo. Cumpre realçar que o conceito de desqualificação social valoriza o caráter multidimensional, dinâmico e evolutivo da pobreza e o status social dos pobres socorridos pela assistência (Paugam, 1999, p. 68).

A construção conceitual da desqualificação social empreendida por Paugam é realizada buscando compreender situações que ocorreram gradativamente em países que já conheceram razoável desenvolvimento econômico-social e que, a partir das novas etapas do desenvolvimento contemporâneo, passam a discriminar segmentos cada vez mais amplos da população (Véras, 2003).

Pode-se dizer que, no caso francês, analisado mais de perto por Paugam, a desqualificação social encontra-se relacionada à crise do Estado Providência, ao fenômeno da exclusão dos trabalhadores do mercado formal de trabalho e à relação dos indivíduos inseridos nesse contexto com os serviços de assistência social característicos do modelo francês.

Nessa conjuntura, a desqualificação social revela uma nova forma de pobreza. Os efeitos dessa pobreza dizem menos respeito a situações de carências em termos materiais, 
passando a estar relacionados a situações de assistência. Nesse sentido, Paugam retoma as idéias de Simmel, para quem ${ }^{3}$

O fato de alguém ser pobre não significa que pertença a uma categoria específica de pobres. Não obstante ser um pobre comerciante, um pobre artista, um pobre empregado, mas continua se situando numa categoria definida por uma atividade específica ou posição. Nessa categoria, ele pode ocupar devido à sua pobreza uma posição que se modificará gradualmente. Mas os indivíduos que, em diversos status e ocupações, se encontram nesta situação, eles não ficam ainda reagrupados de alguma maneira numa totalidade sociológica particular, distinta da classe social à qual pertencem. É a partir do momento que passam a ser assistidos, talvez mesmo quando sua situação poderia normalmente lhe dar direito à assistência, mesmo antes desta lhes ser concedida, que eles se tornam parte de um grupo caracterizado pela pobreza. Esse grupo não permanece unificado pela interação entre seus membros, mas pela atitude coletiva que a sociedade em sua totalidade adota em relação a ele (Simmel, citado por Paugam, 2003, p. 54).

O autor enfatiza ainda que nesse caso, "o que é sociologicamente pertinente não é a pobreza em si, mas as formas institucionais que esse fenômeno assume numa dada sociedade ou num determinado meio" (Paugam, 2003, p. 55).

Contudo, embora o fenômeno da pobreza seja recorrente em nossa sociedade, no Brasil, em se tratando de desqualificação social, a situação apresenta algumas diferenças. A construção conceitual da desqualificação empreendida por Paugam está atrelada a uma realidade diversa da nossa. Isso faz com que tenhamos que adotar certas precauções quanto a sua aplicação em estudos que abordem a realidade brasileira, pois, em nosso país, não se pode fazer referência à perda de um patamar social de cidadania e de assistência exatamente da mesma forma como no caso francês. $O$ fato de não termos atingido um estágio avançado de cidadania como o constituído pelo Estado Providência deve ser considerado; nesse sentido, para que possamos ter uma maior clareza epistemológica do conceito de desqualificação social e de seu uso enquanto categoria analítica, é conveniente que retomemos a literatura brasileira que aborda os temas da exclusão e da pobreza.

\section{O debate sobre a pobreza e a exclusão no Brasil}

No Brasil, o tema da pobreza, e conseqüentemente da desigualdade, faz parte da agenda de pesquisas há pelo menos meio século. Vários estudos envolvendo a temática foram produzidos entre as décadas de 1950 e 1970. Naquele momento, os pesquisadores, ao analisarem o fenômeno da pobreza, recorriam na maioria das vezes à noção de marginalidade, como se pode verificar nos trabalhos de Foracchi (1982), Pereira (1971) e Paoli (1974), entre outros.

Para Pereira (1971), a marginalidade é uma forma específica de incorporação social. Sua argumentação procura demonstrar que as formações capitalistas periféricas comportam em sua estrutura um contingente populacional marginal, sendo essa população uma decorrência da superabundância de mão-de-obra. Esse fato permite ao autor caracterizar a marginalidade como realidade estrutural ligada às contradições do modo de produção capitalista em uma dinâmica de participação-exclusão. $\mathrm{O}$ desenvolvimento econômico nas formações subdesenvolvidas periféricas é um desenvolvimento excludente, que como característica apresenta um contingente de trabalhadores que participam no mercado de trabalho como ofertantes de mão-de-obra sem serem necessariamente absorvidos.

3 George Simmel (1971). The poor (citado por Paugam, 2003). 
Para Foracchi (1982), essa forma de perceber a questão contempla respectivamente o nível econômico (fatores de produção) e o político (relações de dependência), e suas variáveis configuram e determinam a noção de marginalidade. Dessa forma, as populações marginais averiguadas no campo de investigação

(...) aparecem para a investigação como situadas nas fímbrias ou nos limites das necessidades de consumo da força de trabalho (...) sua existência é definida pela participação-exclusão e desta perspectiva é legítima a afirmação de que a marginalidade é uma forma específica de participação e essa marginalidade ocorre tanto nos setores afluentes ou dominantes, quanto nos setores marginalizados de cada sistema econômico, global, capitalista, periférico, contemporâneo (Foracchi, 1982, p. 12).

Contudo, essa maneira de conceber o problema da marginalidade ganhará contornos adicionais. Com Foracchi (1982), a apreensão conceitual da marginalidade referenciada na participação-exclusão passa a não se esgotar nos níveis político e econômico. Sua abordagem sugere que:

(...) a noção de marginalidade, com conotação de participação-exclusão, não se esgota nos níveis políticos e econômicos. Ela se esclarece na medida em que a investigação seja capaz de se propor à identificação do nível cultural como expressão simbólica do econômico e do político, apreendendo, ao mesmo tempo, como esses níveis em estruturas distintas de significação (...) a participação-exclusão expressa, assim, um processo de interiorização da objetividade, ou seja, uma modalidade de experiência do campo das carências. Sob esse aspecto, é menos uma definição de um enfoque segundo o qual o comportamento representa uma interiorização de uma situação objetiva (Foracchi, 1982, pp. 12-13).

Também em Paoli (1974), encontraremos presente tal visão. A marginalidade, para a autora, igualmente traduz-se por um tipo de exploração da força de trabalho requerida pelo capital nas economias dependentes. A situação de marginalidade é demonstrada pelos graus de participação econômica e cultural, na qual o marginal seria considerado como "um tipo humano cujo papel é de 'sobra' em relação às estruturas fundamentais da sociedade em que se insere - no caso, as formações capitalistas periféricas" (Paoli, 1974, p. 145). Além disso, suas formulações em trabalho e marginalidade apontam para uma oposição entre os que eram reconhecidos como trabalhadores assalariados e os maloqueiros, "linguagem esta que identificava com base na maneira de morar, um tipo humano desqualificado socialmente" (Paoli, 1974, p. 76).

Segundo Leal (2004), um apanhado geral sobre as teorias da marginalidade demonstra que a noção diz respeito a vários fenômenos que significam uma forma de exclusão dos benefícios possíveis das sociedades urbano-industriais; leia-se baixa qualidade de moradia, precário acesso a serviços de saúde etc. Assim, a marginalidade é definida como carência em relação à inserção no mercado de trabalho, à proteção social e à cidadania. Ou seja, a marginalidade surge como uma insuficiência em relação à inserção no mercado de trabalho, à proteção social, à habitação, à cidadania e ao consumo.

Essa maneira de perceber o problema não se transforma completamente nas décadas posteriores, permanecendo mesmo quando a noção de exclusão social surge com mais força no centro do debate. No Brasil, desde meados da década de 1980 e mais intensamente nos anos de 1990, as ciências sociais passam a explorar a questão da exclusão. Naquele momento, o debate acerca do tema ganhou corpo e intensificou-se fortemente, seja no meio acadêmico ou fora dele. Em alguns casos o termo se refere a situações diferenciais como a ruptura de laços sociais ou formas precárias de inserção ou, ainda, ao não acesso a bens materiais e simbólicos. As situações abarcadas pelo termo são múltiplas e distintas: "moradores de favelas, trabalhadores sem-terra, desempregados mesmo de classe média, idosos, toxicômanos, 
mendigos e outros são considerados como excluídos, para interlocutores diferentes" (Leal, 2004, p. 2).

Ponderando acerca da freqüência com que o termo exclusão social aparece e a diversidade de situações a que ele faz referência, torna-se difícil saber exatamente a que ele alude. Autores como Martins (1997) criticam esse uso impreciso do conceito; segundo suas observações, presenciamos uma espécie de:

(...) fetichização da idéia de exclusão e certo reducionismo interpretativo que suprime as mediações que se interpõem entre a economia propriamente dita e outros níveis e dimensões da realidade social; e também, entre economia e outros âmbitos de interpretação do mundo da vida (...) todos os problemas sociais passam a ser atribuídos a essa coisa vaga e indefinida a que chamam de exclusão, como se a exclusão fosse um deus-demônio que explicasse tudo. Quando na verdade não explica nada (pp. 15-16).

Assim, o autor critica a generalização do conceito de exclusão ao mesmo tempo em que lança as bases para a sustentação da idéia da inexistência da exclusão, em favor da idéia de contradição. Dessa forma, Martins (1997) propõe que:

Rigorosamente falando não existe exclusão: existe contradição, existem vítimas de processos sociais, políticos e econômicos excludentes; existe o conflito pelo qual a vítima dos processos excludentes proclama seu inconformismo, seu mal-estar e sua reivindicação corrosiva. Essas reações, por não se tratarem de exclusão, não se dão fora dos sistemas econômicos e dos sistemas de poder. Elas constituem o imponderável de tais sistemas, fazem parte deles ainda que os negando (p. 14).

Ao mesmo tempo, observa a permanência de uma intranqüilidade teórica em relação à exclusão proveniente de uma mudança nos modos de explicá-la conceitualmente.

Na verdade, a categoria exclusão é resultado de uma metamorfose nos conceitos que procuravam explicar a ordenação social que resultou no desenvolvimento capitalista. Mais do que uma definição precisa de problemas, ela expressa uma incerteza e uma grande insegurança teórica na compreensão dos problemas sociais da sociedade contemporânea (Martins, 2003, p. 27).

Acrescente-se a essa consideração o fato de que, mesmo com autores criticando o conceito de exclusão e afirmando sua não-existência, o termo é adotado como sinônimo de pobreza. Nesse caso, o que chamamos de exclusão corresponde ao que conhecemos por pobreza. Assim sendo, importa para nós atentar para o fato de que, ao mudarmos o nome de pobreza para exclusão, podemos estar dissimulando o fato de que a pobreza hoje tenha mudado de forma, de âmbito e de conseqüências. Dessa forma, a conclusão do autor consiste em demonstrar que a pobreza hoje inclui a negação subjetiva da pobreza; mais do que privação econômica, há nela certa dimensão moral, não oferecendo mais alternativa nem mesmo a possibilidade remota de ascensão social (Martins, 2004, p. 18).

Cabe aqui uma pequena ressalva: pobreza e exclusão não podem ser concebidas simplesmente como sinônimos de um mesmo fenômeno, embora encontrem-se articuladas. Dessa forma,

Embora não se constituindo em sinônimos de uma mesma situação de ruptura, de carência, de precariedade, pode-se afirmar que toda situação de pobreza leva a formas de ruptura do vínculo social e representa, na maioria das vezes, um acúmulo de déficit e precariedades. No entanto, a pobreza não significa necessariamente exclusão, ainda que possa a ela conduzir (Sawaia, 1999, p. 22). 
Em síntese, para os críticos, apenas a idéia de excluído é insuficiente e não explica muito acerca do fenômeno. Além disso, o conceito aparece despido de uma compreensão histórica, pois na sociedade capitalista não podemos versar sobre uma exclusão absoluta, uma vez que sua dinâmica baseia-se em processos de exclusão para incluir segundo regras e lógicas próprias.

Para Martins, é característica desta sociedade o desenraizamento, que constitui um processo de modificação dos indivíduos em relação àquilo que eles eram. Em sua ótica, o sistema precisa transformar cada indivíduo em membro da sociedade e a maneira pela qual isso ocorre pode ser como produtores ou como consumidores de mercadorias. Dessa maneira, o que deve ser analisado é a forma de inclusão na sociedade. A esse processo o autor dá o nome de inclusão precária ou marginal. A inclusão marginal é um processo inerente à forma de produção e acumulação capitalistas; trata-se de um processo em que as escolhas oferecidas aos cidadãos são insuficientes para reverter o quadro de privação em que estão inseridos (Martins, 1997, 2003).

Dessa perspectiva, o problema da exclusão define-se na maneira encontrada pelos indivíduos para participar desta sociedade, ou seja, nas formas utilizadas pelos indivíduos para realizarem sua inserção. Nesse sentido, torna-se elucidativo o exemplo das meninas prostitutas de Fortaleza. Destaca Martins (2003):

(...) elas não são excluídas, ao contrário: elas são meretrizes justamente para ganhar o dinheiro que viabiliza sua inclusão na economia e no mercado. Com esse dinheiro elas (e suas famílias) se tornam, de algum modo, consumidoras. Porque é com o dinheiro que elas ganham na prostituição, na sua exclusão moral, que elas se incluem na economia. Elas se tornam compradoras, elas alimentam esse sistema com a prostituição infantil. Por isso o problema está em discutir as formas de inclusão, o comprometimento do caráter desses membros, das novas gerações, desde cedo submetidos a uma socialização degradante. $\mathrm{O}$ que a sociedade capitalista propõe hoje aos chamados excluídos está nas formas crescentemente perversas de inclusão (p. 124).

Para Bader Sawaia, estamos todos incluídos de alguma forma no circuito reprodutivo das atividades econômicas. Porém essa inclusão nem sempre se dá de forma digna e decente, sendo que a grande maioria encontra-se inserida através da insuficiência e das privações, que se desdobram para fora do econômico, incluindo a dimensão psicossocial de forma contundente (Sawaia, 1999, p. 8).

Nessa direção, é útil perceber que a nova dinâmica da sociedade capitalista exclui e demora a incluir:

O momento transitório da passagem de exclusão para inclusão está se transformando num modo de vida que permanece: o modo de vida do excluído que permanece que não consegue ser reincluído. E tal modo de vida compromete sua dignidade, sua capacidade de ser cidadão, sua condição humana, do ponto de vista moral e político (Véras, 1999, p. 40).

Tal constatação adquire relevância, pois consideramos que no caso brasileiro o processo de desqualificação social surge em decorrência do modo pelo qual um contingente expressivo da população acaba por inserir-se na sociedade e as implicações dessa inserção nas suas condições de vida. Ou seja, através de uma forma subordinada de integração, precária e instável: a inserção marginal. Trata-se de indivíduos possuidores de renda insuficiente, com baixa instrução, que vivem em sub-habitações etc.

Vivenciar essa forma de inserção é, sobretudo, experimentar trajetórias e modos de vida que comprometem sua dignidade, sua capacidade de ser cidadãos, sua condição humana, 
do ponto de vista moral e político. Sawaia (1999), ao comentar as formulações de Martins a respeito da inclusão marginal, destaca que:

(...) além da humanidade formada de integrados (ricos e pobres), inseridos de algum modo no circuito de atividades econômicas e com direitos reconhecidos, há uma outra humanidade no Brasil, crescendo rápida e tristemente através do trabalho precário, no pequeno comércio, no setor de serviços mal pagos, tratados como cidadãos de segunda classe. Entre esses dois mundos, há uma fratura cada vez maior e difícil de ultrapassar (p. 40).

Isso equivale a dizer que o processo de desqualificação social está relacionado à convivência cotidiana dos indivíduos com um misto de situações de precariedade e de vulnerabilidade. Nessa dinâmica, a desqualificação social e as situações conseqüentes acabam por se correlacionar com o plano psicossocial dos indivíduos. Essa forma de inclusão, quando vivenciada no dia-a-dia, traz embutido um sentimento de desumanização ou de coisificação do ser humano, constituído por uma multiplicidade de dolorosas experiências cotidianas de privações, de anulações e também de inclusão enganadoras (Martins, 2003, p. 21).

Em face ao exposto - retornando à desqualificação social -, enquanto uma categoria, ela apresenta-se como o processo no qual indivíduos em situação de marginalização revestemse de um status de inferioridade social, que além de impedi-los de aprofundar um sentimento de pertencimento, serve de barreira que impede a inserção adequada como cidadão. Em outros termos, trata-se de um processo percebido através de uma trajetória de vida (visto de forma longitudinal), na qual experiências e situações estigmatizantes são vivenciadas e interiorizadas, com efeitos negativos sobre as condições sócio-políticas e sobre a auto-estima.

Uma das características centrais desse processo é que o indivíduo, ao tornar-se um desqualificado social, perde ou não adquire qualidades que o recomendariam à consideração pública. Um dos exemplos mais emblemáticos desses processos é a categoria profissional dos recicladores de lixo, ou catadores, como são chamados. Em texto recentemente publicado, Boaventura de Sousa Santos (2007) comenta sua experiência ao visitar o VI Festival do Lixo e Cidadania, realizado em Belo Horizonte por iniciativa do Movimento Nacional dos Catadores de Materiais Recicláveis (MNCR):

Aprendi que os seres humanos, mesmo os mais excluídos e nas condições mais indignas - aqueles para quem o nosso lixo é um luxo e o endereço é um viaduto ou uma soleira de porta - não desistem de lutar por uma vida digna, assente na reivindicação de direitos de cidadania que, apesar de impunemente desrespeitados, lhes dão notícia da sua humanidade. São milhares de sombras móveis coladas a carroças desengonçadas que percorrem as cidades, atrapalhando os postais ilustrados e a indústria turística, populações descartáveis apesar de ganharem o seu sustento colectando para reciclagem o que descartamos como papel velho, vidro e plástico usados ou sucata. Aprendi que muitas das lutas mais exigentes pela inclusão social exigem formas de organização e mobilização autónomas, já que as agendas dos partidos não contemplam as aspirações dos mais excluídos e os sindicados não reconhecem formas de trabalho que extravasam do modelo do capitalismo industrial (p. 1).

A fala da coordenadora da Associação de Catadores de Papel, Papelão e Materiais Recicláveis de Belo Horizonte (ASMARE) torna-se emblemática nesse sentido; em entrevista sobre sua vida, antes de participar da associação, a coordenadora destacou: "(...) naquela época, nós não nos considerávamos gente. A gente dizia, nós somos bichos mesmo (...)”. A superação desse patamar passa a ser desejado e buscado, por aqueles que se encontram nessa situação, quando entram em associação com outros atores sociais que lhes fazem vislumbrar essa possibilidade. No caso dos catadores, as associações e cooperativas podem cumprir esse papel, conforme demonstra estudo recente (Pizzio, 2007). 
Outra característica da desqualificação é que ela implica em uma invisibilidade produzida, em uma posição de existência tão "inferior" que não pode ser considerada como alternativa credível de vida, passando a ser ignorada pela sociedade. Essa invisibilidade encontra sua melhor expressão na noção de ausência, desenvolvida por Boaventura de Sousa Santos (2004). Em Para uma sociologia das ausências e das emergências, o autor procura demonstrar que o que "não existe", na realidade, foi produzido para permanecer oculto, através de relações sociais injustas e predatórias. Essa constatação adquire relevância, pois implica em perceber que a ausência constitui-se num artifício que permite a naturalização da desigualdade entre indivíduos supostamente mais qualificados e aquela população considerada desqualificada. Esse artifício surge como resultado de um acordo social excludente, que não reconhece a cidadania para todos, no qual a cidadania de uns é distinta daquela de outros, assim como também são distintos seus direitos, suas oportunidades e seus horizontes. Por isso o autor refere a urgente necessidade de um novo contrato social (Santos, 2002). Iremos desenvolver em maior detalhe esse conceito, na próxima seção. Mas já apontamos para a relação que existe entre o trabalho de Santos e as outras formulações sobre inclusão marginal ou desqualificação social.

Segundo Sawaia (1999), a naturalização do fenômeno da exclusão e o papel do estigma (dois dos componentes centrais no processo de desqualificação social):

(...) servem para explicar, especificamente no caso da sociedade brasileira, a natureza da incidência dos mecanismos que promovem o ciclo de reprodução da exclusão, representado pela aceitação tanto do nível social, como do próprio excluído, expressa em afirmações como "isso é assim e não há nada para fazer". Por outro lado, revela também uma fragilização do vínculo societal. Tanto a atmosfera social de conformismo, como a compreensão da condição da exclusão social como fatalidade são reveladoras de processos nos quais os vínculos sociais estão no mínimo fragilizados. Esse caráter natural do fenômeno vem contribuir com o denominado ciclo de exclusão, no sentido de reforçá-lo e reproduzi-lo. O estigma definido como cicatriz, como aquilo que marca, denota claramente o processo de qualificação e desqualificação do indivíduo no ciclo da exclusão (p. 23).

Por fim, destacamos que o fenômeno da desqualificação social não é exclusividade de grupos isolados, pelo contrário, situações que podem conduzir a processos de desqualificação são percebidas em estratos sociais diferenciados.

Como um referencial teórico capaz de dar conta (pelo menos parcialmente) da compreensão dessa complexa realidade, recorremos agora à sociologia crítica de Boaventura de Sousa Santos, a partir dos seguintes conceitos: dialética da regulação e emancipação social, noção de autoria e sociologia das ausências.

\section{A sociologia crítica de Boaventura de Sousa Santos}

$\mathrm{Na}$ tentativa de responder à pergunta "porque se tornou tão difícil produzir uma teoria crítica?", o autor realiza uma crítica da forma de conhecimento e das práticas sociais vigentes desde o advento da modernidade ocidental, sem perder de vista sua idéia de que teoria social crítica é toda teoria que não reduz a realidade ao que já existe, meramente como existe, mas sim a considera um devir pleno de possibilidades.

Em sua perspectiva, a partir dos séculos XVI e XVII, a modernidade ocidental emergiu como um ambicioso e revolucionário paradigma sócio-cultural, em uma tensão dinâmica entre regulação social e emancipação social. A partir de meados do século XIX, 
com a consolidação da convergência entre o paradigma da modernidade e o capitalismo, a tensão entre a regulação social e a emancipação entrou em um processo histórico de degradação, caracterizado pela gradual e crescente transformação das energias emancipatórias em regulatórias (Santos, 2002).

Esse paradigma que, segundo o autor, poderia ser representado pelo positivismo - em suas várias formulações -, assentava-se na distinção entre sujeito e objeto e entre natureza e cultura. Seu argumento central é que estamos vivenciando a crise desse conjunto de pressupostos e das práticas sociais que eles geraram, ou seja, vivenciamos uma transição paradigmática, expressa nos níveis epistemológico e societal. Assim, com o colapso da emancipação na regulação, o paradigma da modernidade deixa de poder renovar-se e entra em crise (Santos, 2004).

Ou seja, o paradigma sócio-cultural da modernidade, constituído antes do capitalismo, transforma-se em modo de produção dominante e desaparecerá provavelmente antes mesmo de o capitalismo perder a sua posição dominante. Esse desaparecimento é um fenômeno complexo, já que é simultaneamente um processo de superação e um processo de obsolescência. É superação na medida em que a modernidade cumpriu algumas promessas, sendo que, em alguns casos, até com excesso; é obsolescência na medida em que a modernidade não consegue cumprir outras promessas, dentre elas o progresso com prosperidade, o equacionamento dos problemas sociais pela via da ciência e da tecnologia etc. (Santos, 2001).

Ao desnudar a complexidade do paradigma da modernidade, o autor ressalta seus dois pilares de sustentação: a regulação e a emancipação social. Ao fazer esse movimento, recorre a Hobbes para demonstrar que o pilar da regulação sustenta-se sob a égide do Estado, do mercado (princípio formulado por John Locke e Adam Smith) e, por fim, no principio da comunidade (princípio formulado por Jean-Jacques Rousseau). Já no que diz respeito à emancipação, recorre a Max Weber e suas três lógicas de racionalidade: a racionalidade estético-expressiva, a racionalidade instrumental da ciência e da tecnologia e a racionalidade prático-moral da ética e do direito.

Como destacamos anteriormente, Santos bebe na fonte da teoria social crítica moderna, de base marxista, para posteriormente buscar superá-la. Sua divergência com a dimensão mais necessitária do marxismo centra-se no fato de que a tradição marxista entendia a possibilidade de superação do atual estágio de desenvolvimento baseada em um principio único de transformação social. Havia uma perspectiva emancipatória (o ideal revolucionário) com um ator social privilegiado para levá-lo a cabo (a classe operária). A conseqüência desse fato foi que a teoria crítica interpretou esse princípio com grande liberdade, compartilhando com a sociologia convencional alguns aspectos importantes.

O primeiro aspecto é a idéia de agentes históricos, ao qual corresponde a dualidade entre estrutura e ação assumida pela teoria critica tradicional. Santos assume, nesse caso, uma posição contrária, para a qual não há um processo único de transformação social, enfatizando que mesmo aqueles que continuam a crer num futuro socialista o vêem como um futuro possível, em concorrência com outros, alternativos. Disso decorre que não há agentes únicos, como também não há forma única de emancipação ou de dominação. Sendo estas últimas múltiplas e plurais, variadas também serão as formas de resistência e de emancipação a serem empreendidas. Nisso reside sua proposição de uma teoria crítica pós-moderna ou póscolonial, no sentido de superar os traços reificantes e universalizantes da teoria crítica moderna. Em um contexto de grande diversidade social, fragmentação do real, multiplicidade de atores emergindo na esfera pública, também a teoria social deve renovar-se.

O segundo aspecto importante a destacar é que a teoria crítica de base marxista, a exemplo da sociologia convencional, viu na industrialização o mote do desenvolvimento. Para Boaventura Santos, a relação desenvolvimento/industrialização é um embuste, não 
sendo esta a "parteira" do desenvolvimento. Sua argumentação sustenta-se no fato de a industrialização se assentar, por um lado, numa concepção retrógrada da natureza, incapaz de ver a relação entre a degradação desta e a degradação que ela sustenta; por outro lado, para dois terços da população mundial, a industrialização não trouxe desenvolvimento traduzido por melhores condições de vida, o que por si só já é significativo. A própria esquerda política - e veja-se o caso brasileiro com o governo Lula - ainda aposta no desenvolvimento, no crescimento econômico baseado em industrialização e agrobusiness como forma de sanar os graves problemas sociais enfrentados pelos países de periferia.

O paradigma da modernidade almejava um desenvolvimento harmonioso entre os dois pilares (regulação e emancipação) e pretendia ainda que esse desenvolvimento traduzisse-se na completa racionalização da vida coletiva e individual. Essa vinculação entre os pilares e a práxis social iria garantir a harmonização de valores sociais necessários ao equilíbrio das sociedades.

Porém, o que se viu foi um desenvolvimento desequilibrado, no qual o pilar da emancipação míngua em relação ao da regulação, tendo como conseqüência para o último a hipertrofia do mercado em detrimento dos princípios do Estado e da comunidade, processo que desemboca em uma ideologia mundial de consumismo. A redução da emancipação à racionalidade instrumental e a redução da regulação ao princípio de mercado, incentivado pela conversão da ciência na principal força produtiva, constituem a condição determinante que levou a emancipação moderna a render-se à regulação moderna. Nesse processo, a emancipação deixou de ser o outro da regulação para se transformar em seu duplo. Assim, a absorção da emancipação pela regulação neutralizou os receios outrora associados à perspectiva de uma transformação social profunda de futuros alternativos (Santos, 2001, p. $57)$.

Mas as divergências do autor com a teoria social moderna não se esgotam aqui; outro ponto de relevância diz respeito ao estatuto e aos objetivos da própria crítica. Para Santos (2001), todo pensamento crítico é centrifugo e subversivo, na medida em que visa criar desfamiliarização em relação ao que está estabelecido e é convencionalmente aceito como normal, inevitável e necessário. Mas enquanto na teoria crítica moderna o objetivo do trabalho crítico é criar desfamiliarização, aí residindo o seu caráter vanguardista, para o autor o objetivo da vida não pode deixar de ser a familiaridade com a vida. Por isso, a desfamiliarização é por ele concebida como um momento de suspensão, necessário para criar uma nova familiaridade; assim, o objetivo último da ciência social crítica é ela mesma se transformar em um novo senso comum, um senso comum emancipatório (Santos, 2000, p. 16). Aqui reside uma das idéias-chave do autor.

Para ele, deixou de ser possível conceberem-se estratégias emancipatórias genuínas no âmbito do paradigma dominante, já que todas elas estão condenadas a transformarem-se em outras tantas estratégias de regulação. Assim, em um movimento metodológico de dupla escavação, busca, no "lixo" cultural produzido pelo cânone da modernidade ocidental, as tradições e alternativas que dele foram expulsas. No colonialismo e no neocolonialismo, procura, entre os escombros das relações dominantes entre a cultura ocidental e outras culturas, relações mais recíprocas e igualitárias.

Resumidamente, tem dedicado-se a trabalhar na emergência de um novo paradigma epistemológico-sócio-político, no qual se pensem as transformações e as possibilidades para além do capitalismo e para além das alternativas ao capitalismo produzidas pela modernidade ocidental. Para tanto, o autor tem sido pródigo na criação de conceitos capazes de avançar nessa proposta. Tais conceitos têm encontrado guarida e grande repercussão nas ciências sociais e, por esse motivo, consideramos possível sua aplicabilidade no contexto da análise da desqualificação social. Passamos abaixo a apresentar os conceitos e justificar a sua utilização. 


\section{Os conceitos e sua aplicabilidade}

\section{Dialética entre regulação e emancipação}

Como já referimos anteriormente, o autor distingue na modernidade dois pilares em tensão dialética: o pilar da regulação e o pilar da emancipação social. Embora ele próprio considere que essa dialética fez-se presente de forma mais intensa na realidade da comunidade européia e países avançados, não dando conta das relações nos países colonizados (Santos, 2004), consideramos que ela abre um leque de possibilidades de análise justamente pelo fato da sociedade brasileira ter no mercado seu agente de regulação e ter no Estado ainda um mediador. Dessa forma, as possibilidades de emancipação, aqui entendidas na forma de acesso a cidadania plena, deverão dar-se no espaço público; e é também nesse âmbito que se gestam as possibilidades de rompimento com a dependência social e a desqualificação por parte dos atores vulnerabilizados, o que permite analisar todo um conjunto de resistências à dominação que ele chama de "cosmopolitismo subalterno". Esse conceito expressa uma grande diversidade de práticas, movimentos sociais, concepções alternativas de vida, de economia, comércio, sociedade e comunidade. A economia solidária pode ser descrita como uma prática do cosmopolitismo subalterno; o movimento Fórum Social Mundial é talvez sua principal forma de expressão, através da diversidade de demandas que expressa. $O$ uso do termo cosmopolita aqui não se confunde com "ser cidadão do mundo" - conceito sem dúvida da e para a elite -, mas sim poder apropriar-se de uma condição globalizada e irmanada com pessoas e culturas de outros lugares e olhares na busca de um mundo outro, possível a partir da globalização da esperança e da solidariedade.

Ao feixe de projetos e lutas progressistas globalizadas, Santos $(2002,2003)$ chama cosmopolitismo subalterno. A esses projetos não subjaz uma teoria única ou uma estratégia una. Sua expressão pode ir do movimento zapatista no México, à economia solidária em Porto Alegre ou na Índia. Não há teoria social unificada que possa dar conta plenamente das realidades empíricas diversas que encontramos na contemporaneidade.

\section{Sociologia das ausências}

Boaventura Santos destaca que a opção da sociologia pelo conhecimentoemancipação (para o qual o ponto de ignorância é o colonialismo e o ponto de saber é a solidariedade) remete-nos, entre outras implicações, a uma passagem do monoculturalismo para o multiculturalismo. Entretanto, a construção de um conhecimento multicultural implica em duas dificuldades: o silêncio e a diferença. A expansão da ciência moderna como conhecimento-regulação (para o qual o ponto de ignorância é o caos e o ponto de saber é a ordem) ensejou um processo de destruição de muitas formas de saber e de ser, o que acabou produzindo silêncios sociais, onde se tornaram impronunciáveis as necessidades e as aspirações de povos ou grupos sociais que tiveram suas formas de saber, viver e sentir destruídas, descredibilizadas ou ridicularizadas. Exemplos disso são os povos indígenas, os de origem afro-descendente, as mulheres, os gays e lésbicas, os "loucos" ou portadores de sofrimento psíquico permanente, os trabalhadores empobrecidos pelos processos de industrialização, expansão capitalista, reestruturação produtiva etc. (Santos, 2004).

Tendo como base uma razão totalizadora, a ciência moderna colocou em movimento um processo onde não há compreensão nem ação que não seja referida a um todo e o todo tem primazia sobre as partes que o compõem. O todo, que é na verdade uma das partes que se totaliza pela hegemonia, é representado pelo capitalismo, pelos países ricos e seus agentes, pelo patriarcado, pelo homem (branco, educado, heterossexual etc.). Tudo que não cabe 
nesses parâmetros é arrastado à condição de ausência social ou de uma existência desqualificada. Daí a necessidade de se proceder a uma sociologia das ausências, nomeando os agentes e os saberes marginalizados no intuito de dar-lhes credibilidade, estatuto de existência legítima enquanto tal, não de resíduo ou anacronismo.

Em outras palavras, a sociologia das ausências constitui-se em um procedimento investigativo que intenta demonstrar que aquilo que parece não existir teve essa invisibilidade ativamente produzida por relações sociais injustas e predatórias, ou seja, como uma alternativa não credível em relação ao que existe e é considerado como válido. O seu objetivo é transformar objetos não credíveis em credíveis e, com base nisso, transformar ausências em presenças.

Existem, para o autor, formas específicas de produzir não-existências, que se corporificam em lógicas de pensamento e de práticas sociais. São cinco as lógicas de produção das não-existências (2002, 2004), que constituem monoculturas nas dimensões epistemológica, temporal, de classificação social, escalar e produtiva. Vejamos, brevemente, cada uma delas.

A monocultura do saber, que considera a ciência moderna e a alta cultura como padrões únicos de verdade e qualidade estética, respectivamente. A monocultura do tempo linear, que se constitui na perspectiva hegemônica da temporalidade ocidental, rumo ao progresso futuro. Lógica da classificação social, que cria categorias sociais que naturalizam hierarquias, desigualdades e injustiças; assimetrias entre gêneros, etnias e classes sociais assumem caráter natural e quem é "inferior" jamais será alternativa credível para quem é "superior". A lógica da escala dominante, na qual o global da globalização hegemônica (neoliberal) é a escala por excelência; o local e o particular não constituem alternativas credíveis, a não ser que se submetam às regras dominantes. A lógica produtivista ou monocultura da produtividade capitalista hegemônica, na qual o crescimento econômico é um objetivo racional inquestionável; como a natureza e o trabalho devem estar a serviço dessa lógica, o estéril e o desqualificado para o trabalho não servem, devendo ser descartados. Formas alternativas de produzir, como modos familiares de agricultura orgânica, ou produção em pequena escala oriunda de desenhos organizacionais alternativos, são "atrasados", "primitivos". Os recursos, naturais e humanos, podem ser explorados de forma predatória, em nome do desenvolvimento econômico, objetivo inquestionável.

São cinco, conseqüentemente, as principais formas sociais de não-existência que assume aquele sujeito ou grupo social que foi excluído como alternativa credível, como possibilidade de presença reconhecida e válida na esfera social. Então, o não-existente será $o$ ignorante, o residual, o inferior, o local e o improdutivo. A lógica produtivista, na concepção hegemônica, não pode ser questionada; a produtividade vem antes da saúde dos que trabalham e da preservação ambiental.

Se retomarmos o exemplo da atividade de reciclagem, perceberemos que afora todas as dificuldades relativas à sua realização diária, como locais insalubres, alta exigência em termos de resistência física etc., têm-se uma imagem (construída a partir das monoculturas) desqualificada e estigmatizada àqueles que dela participam. Assim sendo, o trabalho como elemento que serve de suporte para a inscrição daqueles sujeitos na estrutura social passa a fornecer elementos negativos que não recomendam os sujeitos à consideração pública. Em outras palavras, essa desconsideração pública diz respeito a um conjunto de signos opacos, mas imediatamente compreensíveis por todos, posto que inscritos no corpo, na forma de falar, de andar etc. e são imediatamente reconhecidos como sinais de inferioridade. Citamos algumas falas onde se evidenciam tais constatações.

Lixeiros! geralmente eles têm preconceito por não saber mesmo o que tem de bom aqui dentro que eles poderiam aproveitar. Até no colégio mesmo que o meu menino está, eles têm preconceito com ele, dizem, a tua mãe é uma lixeira... ele diz, não minha mãe não é uma 
lixeira... ah, vocês comem do lixo... não, nós temos o trabalho da minha mãe, a gente não come do lixo, a gente come do trabalho dela. Ainda tem muito preconceito (Sirlei, CEA-Vila Pinto).

Eles acham muito nojento. Elas acham nojento porque "ah, vocês vivem do lixo dos outros, do lixo da gente". Vocês têm que mexer nisso. No passado aqui, no passado eu achava muita coisa, muito, teve épocas como de quando inaugurou aqui o galpão, achava placenta, achava ferro, achava até pedaços de pessoas às vezes (Delmar, CEA-Vila Pinto).

Eles olham para gente como se a gente fosse uns lixeiros mesmos, como sempre. Eu te digo que a gente é meio desclassificado quando passa na rua, chamam até... olha o cara juntando lixo aí, lixeiro (Gaudério, Profetas da Ecologia).

A desqualificação atribuída pela sociedade aos catadores manifesta-se igualmente no grupo familiar, no qual uma combinação de vergonha e desprezo serve de obstáculo a apartar sujeitos e impedir uma convivência mútua. Essa situação pode ser caracterizada através da passagem abaixo.

É aquela coisa, se o senhor fosse visitá-los, o senhor ia dizer que era mentira, que são meus irmãos. Eles têm condições, meus irmãos têm carro, a minha irmã que mora na Mathias Velho, a casa dela é um palácio, a escadinha sobe tudo rodeando para os quartos. Então, uma vez até fiquei sentida com ela, ela mesma disse: que eu não era irmã dela porque a minha casa não servia nem de galinheiro pra ela. Todos meus irmãos têm, todos eles. É por isso que ninguém me procura. Nem no velório do meu filho, que eles eram tios e tia de sangue eles não foram (Iracema, Profetas da Ecologia).

A fixação da pobreza como marca de inferioridade e a dificuldade em se livrar dos estigmas operam de maneira contraproducente na construção das identidades sociais. Assim, reproduzem-se e cristalizam-se lógicas que justificam a suposta "inferioridade", naturalizandoa e ainda culpabilizando-se o pobre, o desqualificado, pela sua condição.

A produção social dessas ausências resulta na subtração do mundo, na contração do presente e no desperdício da experiência. A sociologia das ausências coloca a necessidade de pôr em questão cada uma dessas lógicas. Nesse questionamento, propõe substituir monoculturas por ecologias, o que possibilitaria a disputa epistemológica entre diferentes saberes, a vivência de temporalidades diversas da frenética máxima de que tempo é dinheiro, a não identificação da diferença com a desigualdade, a recuperação do que no local não é efeito da globalização hegemônica, a valorização de sistemas alternativos de produção e consumo, eco-socialismo, eco-feminismo etc.

Dessa forma, torna-se possível, através da sociologia das ausências, captar e compreender o processo através do qual têm sido produzidos os silêncios sociais nos mais diversos contextos empíricos e, a partir daí, trazer a tona saberes e perspectivas diferenciadas que possam representar toda a riqueza social contemporânea. Nesse processo, os sujeitos fazem-se autores da sua própria vida e da vida coletiva.

\section{Noção de autoria}

Para Santos (2002), as representações inacabadas da modernidade representam elementos importantes para que o paradigma emergente efetivamente transcenda os limites da modernidade. Um dos caracteres inacabados da modernidade é a racionalidade estéticoexpressiva, que reside, dentre outros, no conceito de autoria. A noção de autor encontra-se relacionada à noção de sujeito individual; contudo esta última, tendo sido desenvolvida no pilar da regulação, derivou para o conceito de indivíduo autônomo como agente do mercado. O conceito de autoria por ele desenvolvido parte da racionalidade estético-expressiva das artes, definindo-se o autor como um criador autônomo, capaz de inventar outros mundos e 
novas realidades para si e para outrem. Assim, enquanto a autoria do indivíduo se baseia no desempenho de ações normativamente reguladas, a autoria do autor assenta na diferença entre a ação e as condições de seu desempenho.

Tendo como ponto de partida a referida noção de autoria, pode-se demonstrar, a partir de historias de vida, como os sujeitos que sofreram processos de desqualificação social, como, por exemplo, trabalhadores empobrecidos, desempregados ou sujeitos a ocupações degradantes, percebem-se como autores de suas próprias trajetórias. Tácito a essa noção encontra-se a concepção de processo, na qual a trajetória é vivenciada como um continuum que permite ao sujeito deixar de perceber-se como objeto e passar a conceber-se como ator, sujeito capaz de experienciar e agir em relação às situações cotidianas, dissolvendo, assim, os laços da impotência frente aos ditames que o sujeitam. A partir dessa constatação, buscamos compreender o contexto subjetivo em que se deram as escolhas e as ações por eles empreendidas, na busca da diminuição do déficit de cidadania e no fortalecimento dos seus vínculos sociais. Essa perspectiva pode ser entendida como a aplicação da sociologia das ausências no campo da pesquisa social.

Por fim, gostaríamos de destacar que a adoção dessa perspectiva teórica para a análise do fenômeno da marginalização social permite perceber que os diversos sujeitos são afetados de diferentes formas pelos cenários de privação e, assim sendo, suas reações também serão diferenciadas, assim como suas possibilidades de superação. É nesse sentido que a noção de autoria permite que o pesquisador possa captar e interpretar as sutilezas que compõem trajetórias individuais e coletivas a partir de situações como o desemprego, o emprego precário ou mal remunerado, informal, instável, o trabalho exercido muitas vezes em condições desumanas e degradantes. Cada autor, nesses contextos, irá interpretar e buscar superar a sua condição através de lógicas e práticas próprias. É dessa perspectiva que interpretamos os esforços de vários catadores que buscam na associação coletiva construir uma alternativa, não só credível, mas valorizada socialmente, que tem como premissa básica a idéia de que os sujeitos são os autores de suas biografias e não resultados de situações contingentes.

\section{Considerações finais}

Cabe ressaltar que neste trabalho não pretendemos esgotar ou apresentar em todos seus aspectos a sociologia crítica elaborada por Boaventura de Sousa Santos. Essa seria uma tarefa por demais abrangente e tampouco julgamo-nos, no âmbito deste texto, capazes de realizá-la. Apresentamos alguns dos seus conceitos, de maneira que, assim o fazendo, pudéssemos deixar clara a adequação que percebemos no que se refere ao uso do seu referencial teórico-metodológico, que nos parece profícuo na investigação empírica dos variados contextos sociais, em especial com sujeitos que sofreram processos de desqualificação social e de invisibilização.

Trazer as ausências para serem presenças, em relação aos modos de ser, viver e trabalhar, é uma perspectiva que pode abrir horizontes fecundos na busca de desenhos institucionais alternativos, abertos à partilha de poder, ao mesmo tempo em que permitam a singularização e a autoria de sujeito individual, reconhecidas nos espaços públicos onde os atores se encontram para produzir a micro-política da vida cotidiana, na ação e no discurso (Jovchelovitch, 2004).

É preciso, contra o saber, criar saberes; e contra os saberes, contra-saberes (Santos, 2000). A transição paradigmática é por demais complexa para que seus territórios sejam navegados apenas com o conhecimento e o instrumental hegemônico das ciências sociais. 
Plena de novas proposições, não é fácil discernir as versões emancipatórias dos seus simulacros regulatórios. Produzir ou re-descobrir saberes é tarefa desafiadora; mas receamos que não nos reste outra escolha, pois não fazê-lo implica em aceitar a realidade como esgotando-se no que já existe, apenas.

\section{Referências Bibliográficas}

Adorno, T. W. (1985). Dialética do esclarecimento: fragmentos filosóficos. Rio de Janeiro: Zahar.

Antunes. R. (1999). Adeus ao trabalho? Ensaio sobre as metamorfoses e a centralidade do mundo do trabalho (6 $6^{\underline{a}}$ ed.). São Paulo: Cortez.

Fundação Getulio Vargas (2004). Evolução recente da miséria. Centro de Políticas Sociais/IBRE.

Foracchi, M. M. (1982). A participação social dos excluídos. São Paulo: Hucitec.

Freitag, B. (1994). A teoria crítica ontem e hoje (5ํㅡㄹ.). São Paulo: Brasiliense.

Goffman, E. (1988). Estigma: notas sobre a manipulação da identidade deteriorada (4⿳亠丷厂 ed.). Rio de Janeiro: Guanabara. (Originalmente publicado em 1963)

Habermas, J. (1988). Teoria de la accion comunicativa. Madri: Taurus.

Henriques, R. (2000). Desigualdade e marginalização no Brasil. Rio de Janeiro: IPEA.

Horkheimer, M. \& Adorno, T. W. (1978). Temas básicos de sociologia (2ª ed.). São Paulo: Cultrix.

Ivo, A. B. L. (2001). Metamorfoses da questão democrática: governabilidade e pobreza (Coleção Becas de Investigación). Buenos Aires: CLACSO.

Jovchelovitch, S. (2004). Psicologia social, saber, comunidade e cultura. Psicologia E⿱ Sociedade, 16 (2), 20-31.

Kowarick, L. (1981). Capitalismo e marginalidade na América Latina (3ํㅡㄹ Ed.). Rio de Janeiro: Paz e Terra.

Kowarick, L. (2003). Sobre vulnerabilidade socioeconômica e civil: Estados Unidos, França e Brasil. Revista Brasileira de Ciências Sociais, 18 (51), 61-85.

Leal, G. F. (2004). A noção de exclusão social em debate: aplicabilidade e implicações para a intervenção prática. XIV Encontro nacional de estudos populacionais-ABEP. Caxambu.

Martins, J. S. (2003). A sociedade vista do abismo: novos estudos sobre exclusão, pobreza e classes sociais (2 ed.). Petrópolis: Vozes.

Martins, J. S. (1997). A exclusão e a nova desigualdade. São Paulo: Paulus.

Paoli, M. C. P. M. (1974). Desenvolvimento e marginalidade: um estudo de caso. São Paulo: Biblioteca Pioneira de Ciências Sociais.

Paugam, S. (2003). Desqualificação social: ensaio sobre a nova pobreza. São Paulo: EDUC e Cortez. (Originalmente publicado em 1991)

Paugam, S. (1999). O enfraquecimento e a ruptura dos vínculos sociais: uma dimensão essencial do processo de desqualificação social. In B. B. Sawaia (Org.), As artimanhas da exclusão: análise psicosocial e ética da desigualdade social (pp. 67-86). Petrópolis: Vozes.

Pereira, L. (Org.). (1978). Populações marginais. São Paulo: Duas Cidades.

Pizzio, A. (2007). A economia solidária e a qualificação social dos trabalhadores empobrecidos. Dissertação de Mestrado, Programa de Pós-Graduação em Ciências Sócias, Universidade do Vale do Rio dos Sinos, São Leopoldo.

Pizzio, A. (2007). A qualificação social nos empreendimentos econômicos solidários de reciclagem. Economia Solidária e Ação Cooperativa, 2 (1), 23-34. 
Quijano, A. (1978). Nota sobre o conceito de marginalidade social. In L. Pereira (Org.), Populações marginais (pp. 11-72). São Paulo: Duas Cidades.

Santos, B. S. (2000). A crítica da razão indolente: contra o desperdício da experiência. São Paulo: Cortez.

Santos, B. S. (2002). Para uma sociologia das ausências e das emergências. Revista Crítica de Ciências Sociais, 63, 237-280.

Santos, B. S. (2003). Poderá o direito ser emancipatório? Revista Crítica de Ciências Sociais, 65, 3-76.

Santos, B. S. (2004). Do pós-moderno ao pós-colonial e para além de um e outro. Coimbra: Centro de Estudos em Ciências Sociais.

Santos, B. S. (2007, 27 de setembro). Lixo e cidadania. Coluna Visão, 27 de Setembro 2007. Disponível em: www.ces.fe.uc.pt. Acesso em 30/09/2007.

Sawaia, B. B. (Org.). (1999). As artimanhas da exclusão: análise psicossocial e ética da desigualdade social. Petrópolis: Vozes.

Véras, M. P. B. (1999). Exclusão social: um problema brasileiro de 500 anos. In B. B. Sawaia (Org.), As artimanhas da exclusão: análise psicossocial e ética da desigualdade social (pp. 27-52). Petrópolis: Vozes.

Véras, M. P. B. (2003). Prefácio da edição brasileira. In S. Paugam, Desqualificação social: ensaio sobre a nova pobreza (pp. 13-30). São Paulo: EDUC e Cortez.

Endereço para correspondência:

alexpizzio2@yahoo.com.br, mariliav@unisinos.br

Recebido em: 05/10/2007

Revisado em: 19/02/2008

Aprovado em: 10/03/2008 